\title{
60. Cheyletid Mites associated with Plants in the Malay Peninsula, with description of a New Species (Acarina: Cheyletidae)*)
}

\author{
By Shôzô EharA**) and AbDUl GHani Ibrahim***) \\ (Communicated by Sajiro Makino, M. J. A., Oct. 12, 1988)
}

Mites of the family Cheyletidae have been recognized as predators of phytophagous mites in some parts of the world. Prior to this study three species of cheyletid mites were recorded from trees and litter in Malaysia (Shiba, 1976). The present paper deals with four other species of Malaysian cheyletids, including one new species. The materials on which this study was based were collected from plants in the Malay Peninsula, mostly by the senior author (SE) and partly by Dr. H. Mori, Hokkaido University.

The holotype of the new species is deposited in the collection of the Biological Institute, Faculty of Education, Tottori University. The terminology generally follows that of Summers and Price (1970).

Hemicheyletia morii Ehara, n. sp. (Figs. 1-4)

Female. Length ratio of gnathosoma to idiosoma $=0.43$. Protegmen rounded in front, surface with mostly rounded microtubercles. Peritremes consisting of 5 pairs of segments; the posteriormost segments noticeably longer than the others. Tegmen with longitudinal microtuberculate striae on anterior part, and transverse microtuberculate striae on middle part; microtubercles on tegmen mostly rounded; posterior part of tegmen with longitudinal striae. Palpal tarsus with 2 comblike setae, 2 sicklelike setae and 1 short rodlike sensillum; outer comb with 17-18 teeth, inner comb with at least 30 teeth. Palpal tibia with 3 lanceolate setae of which the interolateral seta is rather flagellate; claw with 9-10 teeth. Palpal genu with 1 spatulate, spinose, ribbed dorsal seta. Palpal femur stout, strongly swollen on outer side, with rounded microtubercles on upper aspect; with 1 spatulate, spinose, ribbed dorsal seta, 1 similar, smaller ventrolateral seta and 2 simple ventral setae. Propodosomal shield wider than hysterosomal shield; both shields with microtuberculate striae, microtubercles variable in shape (elliptical to fusiform) between parts. A pair of eyes slightly anterior to and slightly outside of 2 nd pair of lateral propodosomal setae. Dorsal interscutal membrane coarsely striate except for the area between tegmen and propodosomal shield; the area with transverse rows of minute microtubercles. Dorsum of idiosoma with 13 pairs of spatulate, spinose ribbed setae: 4 pairs of laterals and 1 pair of medians on propodosomal shield, 5 pairs of laterals and 1 pair of medians on hysterosomal shield; median pair of propodosomals located at level slightly posterior to the 2 nd pair of lateral propodosomals; the 3rd pair

*) Scientific Results of Systematic and Ecological Surveys on Some Plant-parasitic Microarthropods in Southeast Asia, No. 4.

**) Biological Institute, Faculty of Education, Tottori University, Tottori 680, Japan.

***) Department of Plant Protection, Universiti Pertanian Malaysia, 43400 Serdang, Selangor, Malaysia. 


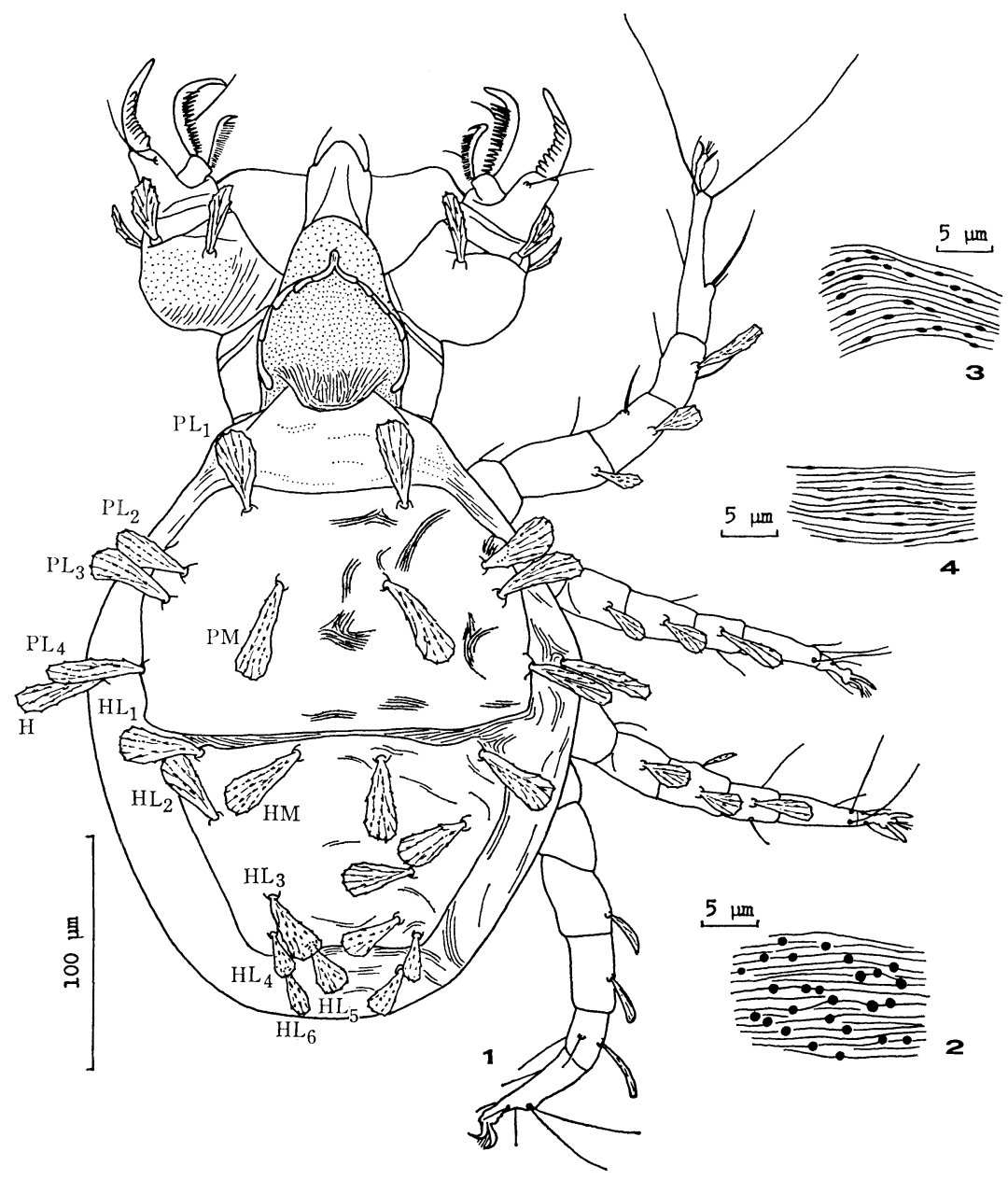

Figs. 1-4. Hemicheyletia morii Ehara, n. sp. ( $\%)$. 1: Dorsum ( $\mathrm{PL}_{1}-\mathrm{PL}_{4}$, lateral propodosomal setae; $\mathrm{PM}$, median propodosomal setae; $\mathrm{H}$, humeral setae; $\mathrm{HL}_{1}-\mathrm{HL}_{6}$, lateral hysterosomal setae; HM, median hysterosomal setae). 2: Striae and microtubercles on tegmen. 3-4: Striae and microtubercles on propodosomal shield.

of lateral hysterosomals more or less in front of the 4 th pair ; 1 pair of humerals and the 6th pair of lateral hysterosomals on interscutal membrane. Venter of idiosoma coarsely striate, with 4 pairs of simple medioventral setae. Two pairs of simple paragenitals, 2 pairs of similar genitals and 3 pairs of somewhat thicker anals. The number of setae and solenidia (in parentheses) on leg segments: coxae 2-1-2-2, trochanters 1-1-1-1, femora 2-2-1-1, genua 2(1)-2-2-1, tibiae 4(1) $-4-4-4$, tarsi 9 (1) -7 (1) -7-7. Measurements in $\mu \mathrm{m}$ (mean \pm S. E., $\mathrm{n}=7$ ) : idicsoma length $266 \pm 4$, idiosoma width $202 \pm 7$, gnathosoma length $115 \pm 1$; lengths of setae: $\mathrm{PL}_{1} 38.7 \pm 0.6, \mathrm{PL}_{2} 38.0 \pm 0.8, \mathrm{PL}_{3} 41.3 \pm 1.2, \mathrm{PL}_{4} 41.2 \pm 1.2$, $\mathrm{PM} 41.9 \pm 0.7$, $\mathrm{H} 38.9 \pm 1.0, \mathrm{HL}_{1} 39.0 \pm 1.1, \mathrm{HL}_{2} 33.7 \pm 0.6, \mathrm{HL}_{3} 33.9 \pm 0.7, \mathrm{HL}_{4} 22.3 \pm 1.2, \mathrm{HL}_{5}$ $23.7 \pm 0.8, \mathrm{HL}_{6} 22.4 \pm 0.9$, HM $37.9 \pm 0.6$, dorsal seta on palpal femur $32.1 \pm 0.5, w \mathrm{I}$ $32.2 \pm 0.9$. 
Male. Not known.

Type-series. Holotype: + , Kepong (Forest Research Institute of Malaysia), Selangor, 21-VIII-1986 (H. Mori), on Ficus maclellandii. Paratypes: 6 ㅇ , 25XII-1987 (H. Mori), bred in Inst. of Appl. Zool. (on Ficus elastica) ; originally collected at Kepong (FRIM), VIII-1986 (H. Mori), on Ficus maclellandii.

Remarks. Hemicheyletia morii is closely related to $H$. transversa CorpuzRaros, 1972 (the Philippines), but differs from the latter in having five pairs instead of seven or eight pairs of peritrematal segments, and in the positions of the third and fourth pairs of lateral hysterosomal setae. The new species is named in honor of Dr. H. Mori.

\section{Hemicheyletia anarbora (De Leon)}

Paracheyletia anarbora De Leon, 1967, p. 34, Fig. 50.

Hemicheyletia anarbora, Summers \& Price, 1970, p. 18; Corpuz-Raros \& Sotto, 1977, p. 154, Fig. 13.

Each of main dorsal shields has one pair of very small, fanlike median setae which are sometimes lobate distally, and sometimes amoeboid. The other dorsal idiosomal setae (11 pairs) are larger, spatulate, spinose and ribbed. The first pair of lateral hysterosomal setae is located on separate platelets.

Previously this species was recorded from Trinidad and the Philippines.

Specimens examined. Kepong (FRIM) : 9 우, 6-VIII-1986 (SE), 4 우, 7-VIII-1986 (SE), on Thyrsostachys siamensis; 4 우, 7-VIII-1986 (SE), 1 우, 11-VIII-1986 (SE), on Gigantochloa levis; 2 우, 11-VIII-1986 (SE), on Bambusa vulgaris ; Port Dickson, Negri Sembilan: 3 우, 15-VIII-1986 (SE), 8 우, 16VIII-1986 (SE), on Bambusa glaucescens; 4 우, 17-VIII-1986 (SE), on Litsea umbellata; 3 ㅇ, 17-VIII-1986 (SE), on Derris sp.

\section{Hemicheyletia wellsina (De Leon)}

Paracheyletia wellsina De Leon, 1967, p. 34, Fig. 52.

Hemicheyletia wellsina, Summers \& Price, 1970, p. 18; Tseng, 1977, p. 216, Figs. 1-3; Corpuz-Raros \& Sotto, 1977, p. 158, Fig. 15.

Two pairs of median setae are located on the propodosomal shield, and one pair of medians is present on the hysterosomal shield. These median setae are hyaline, irregularly branched radially, and rather rosette-shaped. The other dorsal idiosomal setae (11 pairs) are spatulate, spinose and ribbed. The first pair of lateral hysterosomals is set on separate platelets.

This species was previously recorded from Trinidad, Taiwan, and the Philippines.

Specimen examined. Port Dickson: 1 \&, 17-VIII-1986 (SE), on Litsea umbellata.

\section{Cheletogenes monosetosus Tseng}

Cheletogenes monosetosus Tseng, 1977, p. 229, Figs. 18-26.

This species differs from the type-species C. ornatus (Canestrini et Fanzago, 1876 ) in that the hysterosomal shield has only one pair of median setae instead of two pairs.

This mite was previously known only from Taiwan.

Specimens examined. Kepong (FRIM) : 1 \%, 11-VIII-1986 (SE), on Gigantochloa rostrata; Port Dickson: 1 \%, 15-VIII-1986 (SE), 14 우, 16-VIII-1986 (SE), on Bambusa glaucescens.

Addendum. Prior to the present study three species of cheyletids were reported from trees and litter in the Malay Peninsula (Shiba, 1976). Specimens 
of these species were not examined by the present authors.

Hemicheyletia tropica (Shiba), n. comb.

Cheyletia tropica Shiba, 1976, p. 169, Fig. 54A-F.

Eutogenes onoi (Shiba), n. comb.

Cheletogenes onoi Shiba, 1976, p. 171, Fig. 55A-G.

Cheletogenes ornatus (Canestrini et Fanzago).

Acknowledgements. The authors express their appreciation to Dr. H. Mori for submitting a part of the present materials, to Dr. R. L. Smiley for the information of Caribbean cheyletids, and to Mr. K. M. Kochummen for the determination of the plant specimens. They are also thankful to Dr. Salleh bin Mohd Nor and Dr. Tho Yow Pong for their kind and much help during the senior author's stay in Malaysia. Further, they are very grateful to Dr. Sajiro Makino, M. J. A., Professor Emeritus, Hokkaido University, for reviewing the manuscript. This study was supported by Grants-in-Aid for Overseas Scientific Survey, Ministry of Education, Science and Culture, Japanese Government (Nos. 61041003, 62043003).

\section{References}

Canestrini, G., and Fanzago, F. (1876) : Atti Soc. Veneto-Trentina Sci. Nat., 5, 99-111. Corpuz-Raros, L. A. (1972): Philipp. Entomol., 2, 247-271.

Corpuz-Raros, L. A., and Sotto, J. M. (1977) : Kalikasan, 6, 143-170.

De Leon, D. (1967): Some Mites of the Caribbean Area. Allen Press, Inc., Lawrence, Kansas, $66 \mathrm{pp}$.

Shiba, M. (1976): Nature and Life in Southeast Asia, 7, 83-229.

Summers, F. M., and Price, W. P. (1970) : Univ. Calif. Publ. Entomol., 61, 1-153.

Tseng, Y.-H. (1977) : Proc. Nation. Sci. Council, 10, 213-264. 